\title{
The Social and Intellectual Dimensions in the Construction of Scientific Knowledge: The Institutional Theory in Organization Studies in Brazil
}

\author{
Edson Ronaldo Guarido Filho * \\ Email address: edson.guarido@gmail.com \\ Programa de Mestrado e Doutorado em Administração/Universidade Positivo - PMDA/UP \\ Curitiba, PR, Brazil.
}

Clóvis L. Machado-da-Silva

Email address: clms@terra.com.br Universidade Federal do Paraná - CEPPAD/UFPR and Universidade Positivo - PMDA/UP Curitiba, PR, Brazil.

\section{Luciano Rossoni}

Email address: Irossoni@gmail.com

Programa de Mestrado e Doutorado em Administração/Universidade Positivo - PMDA/UP

Curitiba, PR, Brazil.

\begin{abstract}
Based on the assumption that scientific knowledge is a social construction, (re)produced by a community of practicing researchers, in this article we seek to delineate two dimensions of this process. The first, which we have called the social dimension, has to do with the social interactions among researchers in a determined scientific field, being evaluated as a co-authorship network. The second, the intellectual dimension, defined as the programmatic profile expressed by its substantive content and provided references, is constituted in relational citation structures. With this analytical division in mind, we set out to research how the intellectual structure is conditioned by the social relationships among researchers, with a focus on the institutional analysis perspective in organizational studies in Brazil. For this purpose, we empirically evaluated the phenomenon from the convergence of the social network analysis with the scientometric analysis, seeking support for these analyses within the structurationist perspective of the institutional theory. The results point toward a conditioning of the intellectual dimension by the social dimension since there is significant evidence from individual relationships and relationships at the group level that support the argument for a recursive relationship between the two dimensions.
\end{abstract}

Key words: institutional theory; organizational studies; scientific knowledge; social network analysis; scientometrics.

Received 06 May 2009; received in revised form 14 December 2009.

Copyright (C) 2010 Brazilian Administration Review. All rights reserved, including rights for translation. Parts of this work may be quoted without prior knowledge on the condition that the source is identified.

\footnotetext{
* Corresponding author: Edson Ronaldo Guarido Filho

Programa de Mestrado e Doutorado em Administração (PMDA), Universidade Positivo (UP), Rua Prof. Pedro Viriato Parigot de Souza, 5300, Prédio da Biblioteca, $5^{\circ}$ andar, Curitiba/PR, 81280-330, Brazil.
} 


\section{INTRODUCTION}

The number of studies concerning academic collaboration has multiplied in an attempt to understand the construction of scientific knowledge. Under the assumption that science is a collective undertaking, different authors have striven to show the influence that groups of researchers have on the development of science (e.g., Acedo, Barroso, Casanueva, \& Galán, 2006; Barabasi et al., 2002; Braga, Gomes, \& Ruediger, 2008; Li-Chun, Kretschmer, Hanneman, \& Ze-Yuan, 2006; Liu, Bollen, Nelson, \& Van de Sompel, 2005; Machado-da-Silva, \& Rossoni, 2007; Moody, 2004; Newman, 2001a; Otte \& Rousseau, 2002; Rossoni \& Guarido Filho, 2007; Rossoni, Guarido Filho, \& Machadoda-Silva, 2008; Wagner \& Leydesdorff, 2005).

These works have usually focused on aspects concerning the cohesion and closeness of researchers through co-authorship linkages, since this sort of relationship is one of the most tangible and important forms of collaboration in scientific activity (Acedo et al., 2006; Glanzel \& Schubert, 2008). Therefore, collaboration networks, such as co-authorship networks, configure an arena for the sharing of theoretical perspectives and ways of conducting research, as a result influencing knowledge production (Moody, 2004). "Practicing science, in this sense, means being embedded in a set of relationships” (Rossoni \& Guarido Filho, 2009, p. 368).

Following this reasoning, in the fourth edition of the Brazilian Administration Review of 2009 we published an article that described the organization of the scientific field in social networks of collaboration among researchers who adopted the institutional analysis perspective in their studies (Guarido Filho, Machado-da-Silva, \& Gonçalves, 2009). Nevertheless, we asserted that the social expression of the constitution of scientific knowledge in the form of cooperation relationships through co-authorship suggests one among other relevant analytical dimensions.

Under these circumstances, we understand that it is necessary to distinguish two dimensions that are closely related but differently involved in the construction of scientific knowledge. The first, which we have called the social dimension, has to do with current or past social interactions between actors or groups of actors in a given scientific field. The second, which we will refer to as the intellectual dimension is defined as a programmatic profile as expressed by the substantive content and references to other works shared by a set of researchers who adopt it as a valid theoretical framework for scientific practice.

Thus, analytically, it is our belief that research of the construction of scientific knowledge first requires recognizing that we are dealing with an ongoing process, (re)produced by a community of practitioners; and, secondly, that both the social and intellectual dimensions overlap because they are mutually constitutive. Methodologically, we decided to define co-authorship relations as an antecedent of intellectual affinity between researchers by accepting that the social interaction affects how they assess the different theoretical and analytical alternatives available in the scientific field, generating shared cognitive structures.

With this in mind and considering the institutional theory in organization studies in Brazil as our object of analysis, we investigate how the intellectual structure is conditioned by social relationships among researchers. The choice for the analysis of the institutional theory was motivated not only by the growing presence of this perspective in the field of organizational studies, but also, and maybe as a result of its expansion, by the debates in the literature concerning the research objects (Bowring, 2000), the different emphases surrounding key concepts (Hoffman, 1999; Machado-da-Silva, Guarido Filho, \& Rossoni, 2006), levels of analysis (Scott, 2001), analytical categories (DiMaggio \& Powell, 1991; Selznick, 1996), institutionalization mechanisms (Machado-da-Silva \& Gonçalves, 1997; Machado-da-Silva, Guarido Filho, Nascimento, \& Oliveira, 2003), ontological and epistemological assumptions (Hirsch, 1997; Machado-da-Silva, Fonseca, \& Crubellate, 2005) and other critical appreciations (e.g. Alexander \& Smith, 2002; Hasselbladh \& Kallinikos, 2000; Misoczky, 2003 and others). 
To this end, the article has been organized into four sections in addition to this introduction. The first section deals with the theoretical framework upon which the study is based. Considerations concerning the nature of scientific knowledge are discussed so that we can consider the social and intellectual dimensions in more detail. We then describe the methodological procedures that support the empirical part of the study. Next, the results of the study are discussed, in order to highlight the different aspects involved in the interaction between the social and intellectual dimensions. In the final section, we present the conclusions and analytical implications for future studies.

\section{THEORETICAL FRAMEWORK}

In order to conduct this study, we advocate that the scientific field has structural properties that act as both a means and outcome for the actions of agents, according to the structurationist logic defended by Giddens (1984). Therefore, "[scientific] knowledge represents a certain world view which, when shared, influences interpretation and, therefore, the understanding of the phenomena under study" (Guarido Filho, Machado-da-Silva, \& Gonçalves, 2009, p. 301).

Thus, the theoretical framework proposed herein admits that the construction of scientific knowledge, as is the case of the institutional theory in organization studies, is a social process that considers the recurrence between the actions of researchers and socially constructed parameters that establish the limits and possibilities for scientific activities. We also state that it is a social process that embraces an ongoing social and theoretical (re)construction, in accordance to Astley (1985), Davis (2006), DiMaggio (1995), Fuller (2002) and Weick (1995). Therefore, it is subject to evaluation and framing in relation to what is valued in the scientific community.

Under this approach, we understand that we are dealing with the relationship between the social and intellectual dimensions, whose inquiry includes not only relationships structures among agents but also other aspects such as the cognitive/cultural expression of social knowledge, as is the case of scientific articles. However, it is important to state that both dimensions are mutually constitutive and interdependent aspects of the scientific knowledge. Moreover, they represent different levels and units of analysis: while the first level is social, focusing the interaction for cooperation or competition between researchers, the second level is one of ideas and can be studied, for instance, through the system of references used in the objectification of knowledge, as representative of interpretations that are made during intellectual production (Guarido Filho, 2008). Some considerations concerning these aspects will be treated throughout this section. Before that, however, some brief comments on the production of scientific knowledge should be made, based on the work of two prominent authors: Merton and Kuhn.

\section{Scientific Knowledge and the Scientific Community}

According to Merton (1957), science is seen as a social institution expressed in the form of normative imperatives, its ethos, which contain the ideals for scientific practice and provide the bases for how the conduct of scientists is processed and legitimized. Originality, in its turn, is the science's supreme value, and is also associated with the system of recognition and rewards of science, both material and symbolic, and, therefore, with the idea of intellectual property of any knowledge that is produced (Merton, 1957, 1988).

Intellectual property of scientific knowledge is the result of recognition by qualified peers of the validity of the contributions made by a certain scientist when he makes his ideas available for free use by all those that wish to use them. In this way, the reward system of science ensures property of knowledge in that it reinforces institutionalized rules for the public identification of sources (Merton, 1988). The institutionalized practice of referencing other academic works, therefore, expresses not 
only instrumental cognitive functions but also symbolic functions because "they maintain intellectual traditions and provide the peer recognition required for the effective working of science as a social activity" (Merton, 1988, p. 621). In this sense, Merton (1968, p. 4-5) states that "for the development of science, only work that is effectively perceived and utilized by other scientists, then and there, matters”.

Like Merton, Kuhn understands that scientific activity takes place under social parameters. His ideas establish an unprescriptive and unteleological perspective of scientific transformation; "scientific development must be seen as ... evolution from, rather than evolution towards” (Kuhn, 1990, p. 7). Following the Mertonian tradition, Kuhn brought a perspective according to which the social and cognitive dimensions, in terms of knowledge content, should be understood as imbricated. The paradigm "is what the members of a scientific community share, and, conversely, a scientific community consists of men who share a paradigm. ... A paradigm governs, in the first instance, not a subject matter but rather a group of practitioners” (Kuhn, 1970, p. 176 and 180, italics in the original); in other words, it is a worldview at the same time that it denotes a social organization that is gifted with its own values and norms (Kropf \& Lima, 1999). In another text, he goes on to say: "such communities are characterized by the relative fullness of communication within the group and by the relative unanimity of the group's judgment in professional matters [and] will have absorbed the same literature and drawn similar lessons from it" (Kuhn, 1977, p. 296). Therefore, they are the "producers and validators of scientific knowledge" (Kuhn, 1970, p. 178), under which lies the work of the scientists. Thus, the discovery of paradigms depends on research of the behavior of the members of a community while these, alternatively, need to be identified through scientific communications and the knowledge frameworks shared among scientists (Kuhn, 1970, 1990).

In short, we agree with Merton and Kuhn, understanding science as a social field with no privileged epistemic status, in which the construction of scientific knowledge is the result of social interaction and negotiation processes among scientists. From this point of view, science and knowledge respond to the social: epistemic pressures are treated as social pressures. Furthermore, Merton and Kuhn attribute importance to the recognition system, linked to the practice of references, anticipating the development of a research specialty called scientometrics, which in this article helped us to represent the intellectual dimension more objectively.

\section{Intellectual Dimension and Scientometric Analysis}

The intellectual dimension understands the expression of an analytical perspective by its substantive content, objectified in the scientific production and shared by a group of researchers who adopt it as a valid theoretical framework for scientific practice. In this sense, it is closely linked to the field of scientometry, a scientific specialty concerned with understanding socio-organizational processes and knowledge structures of the scientific field as well as their development using mainly quantitative and bibliometric methods (Van Raan, 1997). Scientometry is based on the conception of science as a measurable multidimensional construct and provides an instrument for studies in the field of the sociology of science, especially for the analysis of citations ${ }^{1}$ (Leydesdorff, 2001).

Formally speaking, citations reveal a certain cognitive identification between the citing and cited authors (Van Raan, 1997), since it can be supposed that the act of referencing a work indicates, but does not reveal, what motivated the author to reference a work for the purposes of the ideas that he is producing. Under the normative structure of science (ethos), discussed by Merton (1996), property and recognition are treated as underlying elements in publications, revealed in citations (Small, 2004). In this sense, we agree with Cronin (2004, p. 43) that "citations are much more than baubles dangling from the tails of scholarly texts; they testify to authors common understanding of the bases on which recognition, rights, and rewards are dispensed and managed in contemporary science”. However, Small (2004, p. 72), in accordance with Merton explains that: "when scientists agree on what constitutes prior relevant literature, including what is significant in that literature, they are in fact defining the structures of their communities”. Nevertheless, Leydesdorff (1998, p. 9) emphasizes its multidimensional nature: 
citations are the result of the interaction between networks of authors and between networks of their communications. ... It can function in scientific practices by indicating both the cognitive and the social contexts of a knowledge claim. At a generalized level, citations, as potentially repeated operations, sustain communication in the sciences by drawing upon cognitive and social contexts.

In the words of Wouters (1999, p. 2-3, italics in original),

a researcher is not free to do as he pleases. He must be able to justify his citing action in terms of the norms and rules of his specialty. [Those norms and rules] fulfill the role of a resource which both enables and constrains researchers in their citing. This type of relationship between structure and action, rule and behaviour, is typical of cultural phenomena in general, [defining] the citing culture in science.

Finally, it is worth making an important distinction: to a certain extent, the citation analysis could characterize the intellectual framework used or shared by a set of researchers, but, at least in principle, nothing can be inferred about the social organization of scientific communities directly from citations (Leydesdorff \& Amsterdamska, 1990). This would mean that we would concentrate efforts to the social dimension, for which social network analysis looks very promising for studying the collaboration relationships among researchers (Cronin, 1984, 2008).

\section{Social Dimension and Collaboration Networks}

The social dimension is strongly related to the organization and interaction of researchers or other social units during scientific production. Such activity indicates collaboration which, according to Mullins (1973, p. 18-19)², can take different forms:

(i) communication in the sense of serious discussion about ongoing research; (ii) co-authorship; (iii) the apprenticing, or mentoring, of a student by his or her teacher, and (iv) colleagueship (at the most basic level, two scientists working in the same laboratory).

However, co-authorship is undoubtedly the most formal and visible form of verifying a functional relationship between academics (Acedo et al., 2006; Cronin, 1995), having been considered in this work for the mapping of collaboration relationships between researchers.

Numerous studies have used the analysis of social networks for matters of collaboration in scientific production or to explain the social dynamics and structure of a scientific field. For instance, Liu et al. (2005) studied the co-authorship network to analyze the impact on scientific productivity of authors in the research field of digital libraries. Newman (2001a, 2001b), through scientific collaboration networks, witnessed the influence of intermediaries in the frequency of collaboration between scientists and also the formation of small worlds, aspects which are relevant to understanding the development of the scientific community.

In Brazil, several works were produced on the study of cooperation structures in different areas of management research (e.g. Machado-da-Silva \& Rossoni, 2007; Rossoni \& Guarido Filho, 2007, 2009; Rossoni, Hocayen-da-Silva, \& Ferreira, 2008). Their results showed that there are small world and center-periphery structures in all the fields studied, with implications for the formation of social capital and stratification of scientific production in favor of more collaborative post-graduate programs, research institutions and researchers who played an intermediate role in the relationships with other researchers.

However, despite showing some evidence of knowledge sharing, these studies tend to be limited to the evidence of relationship patterns in scientific production and they have little to say with certainty on this matter without proper analytical depth. There are two reasons for this: the fact that one researcher works with another on a certain work does not mean that there is a consistent intellectual alignment between them and, furthermore, researchers who have never had any direct contact with each other often share a common theoretical and analytical framework. Therefore, in this study we 
sought to deal simultaneously with the social and intellectual dimensions; the methodological procedures of which are outlined below.

\section{Methodological Procedures}

This study is of a descriptive and explanatory nature in that it is concerned, on the one hand, with the characterization of the academic community in terms of its social organization (a social dimension) and the preferences expressed in the form of texts or cited authors (an intellectual dimension). On the other hand, through the interaction of those dimension, the study aim to understand how the scientific knowledge in the institutional perspective in organization studies is conditioned by social relationships.

Data was collected through documentary research of scientific articles published over a period of fifteen years, ranging from $1993^{3}$ to 2007 . Articles were selected based on their main analytical focus guided by the theoretical framework of the institutional theory, providing they were published in the proceedings of the congresses of the Brazilian Academy of Management (ANPAD), which encompass the overall meeting and specific meetings in the fields of organizational studies and organizational strategy, and in Brazilian journals classified as A National ${ }^{4}$, in June 2007, by the Brazilian Governmental Accreditation Agency of Graduate Programs [CAPES], with an editorial line that converges with the field of organizational and strategy studies. The procedures for identifying and selecting these articles involved: (i) an examination of the sources in order to identify articles of interest by analyzing their titles, abstracts, key words and introductory section, (ii) an electronic search of the websites of the sources consulted and (iii) based on the partial results so far, an examination of the lattes curriculum of the twenty most prominent researchers in terms of published articles. These procedures enabled us to triangulate the data sources, ensuring greater reliability regarding the selection of articles.

All the selected articles were coded and tabulated to build an organized database. Data on authorship were extracted and used to trace cooperation relations among researchers in terms of co-authorship. Furthermore, all the cited texts and authors were tabulated and coded according to the list of references of the selected articles, enabling us to conduct citation analyses.

After these stages, 297 articles had been selected, corresponding to the production of 256 researchers. As for references, out of a total of 10,445, we found that there were 4,625 citations of different works and 3,998 valid and distinct cited authors.

Using this data, two major stages of research followed as will be explained below. The research method was quantitative and the data analysis was centered on procedures that are based on the analysis of social networks and citation, complemented by the use of multiple regression techniques.

Stage 1: Constituting the co-authorship network. In order to characterize the social organization of the academic community, we use the co-authorship data of the selected articles to design collaboration networks among researchers in accordance with Liu et al. (2005) and Moody (2004). For this purpose, an incidence matrix for the articles and their respective authors was constructed (a twomode network), so that it could later be transformed into a square matrix of the authors, in which each cell indicates the volume of occurrences of different co-authorship pairs (one-mode network). Graphically, this network illustrates the collaboration structure for scientific production in the field under study. Each node represents a single author and the ties indicate a co-authorship relation at some time during the period under study. Moreover, each group in which researchers are connected to one another is a component, each of which configuring into different spaces for relationships (Wasserman \& Faust, 1994). 
Stage 2: Relationship between the social and intellectual dimensions. To analyze the relationship between the social and intellectual dimensions, the following procedures were used: (1) analysis of the convergence of cited authors by different sets of researchers; (2) construction of an intellectual affinity network; (3) evaluation of the strength of social embeddedness on the intellectual structure, considering in the aggregate the social ties among different groups of researchers; (4) evaluation of the strength of direct relationships (dyads) between researchers on the intellectual structure. For each of these procedures, only the five largest components of the social network of researchers were considered due to their representativeness in terms of the volume of published articles and researchers involved throughout the period under study.

Convergence of references. To verify the sharing of references among different sets of researchers, we constructed a two-mode network in which the relationships of each of the five largest components of the co-authorship network and the authors cited by them are represented. After that, we calculated the indegree centrality of each cited author, so that they could be differentiated according the volume of ties they received from the components, indicating their degree of sharing. As a threshold for graphic representation, only those authors who were cited eight or more times in the database were considered.

Constituting the intellectual affinity network. The intellectual affinity network is configured as a relational structure that no longer expresses social co-authorship as did the first stage of this study but rather the similarity between researchers concerning the references they cite. Graphically, the more similar are the researchers, the closer they will be in the resulting network.

To accomplish this, the matrix with the relationships between researchers and cited authors (twomode) was transformed into a square matrix and then into a matrix of similarity among researchers ${ }^{5}$. In the resulting network, we apply a variable attribute to each researcher. This allowed the identification of each node in relation of the component to which they belonged in the social co-authorship network. During this procedure, only the references shared among the researchers were considered, which naturally eliminated all of those cited exclusively by one researcher. Furthermore, in order to reduce the density of the resulting network, we opted to include only authors who had been cited at least eight times in the database, resulting in a total of 331 authors cited in the intellectual affinity network.

Strength of the embeddedness through ties. This procedure sought to evaluate the tendency of researchers in the same component to cite authors from the intellectual structure of this same component when writing a new article. For this purpose, we used the E-I Index algorithm (Krackhardt \& Stern, 1988) in order to compare the proportion of ties within and outside the partitions (each partition corresponds to the different components identified in the co-authorship network). The analysis was based on the similarity network and because the components originate from social groups, the ties between authors represent the degree of shared references. Thus, values closer to 1 indicate a tendency towards external relationships, or else the inclination to cite authors of the other components intellectual structure. Values closer to -1 show a tendency to establish internal relationships, in other words, the propensity of researchers to cite author that already exist in the intellectual structure of the component they belong. Finally, tests were conducted for different periods: (1) 1993-2007; (2) 2005-2007; (3) 2002-2004; (4) 1999-2001; (5) 1993-1998.

Strength of direct relationships. For this purpose, we asked whether the intellectual structure is influenced by the immediate collaboration relationships among researchers, the dyads. We performed a Double-Dekker MRQAP multi-regression analysis, a procedure that is normally used to test hypotheses based on dyadic relationships in situations in which the independent variables are collinear (Dekker, Krackhardt, \& Snijders, 2007). In general terms, through this procedure it is possible to evaluate whether one type of relationship influences another, which means a network regression analysis, whose unit of analysis is no longer the researcher but rather the immediate ties between them (Hanneman \& Riddle, 2005).

In the present study, two general regression models were constructed for the purpose of evaluating the influence of the dyadic co-authorship relations (independent variables) on the intellectual structure, 
represented through the intellectual affinity network (dependent variable). For both models, two independent variables were defined: the dichotomous co-authorship network, which considers only the existence of the cooperation between researchers, and the valued co-authorship network, which considers not only the link between nodes but the frequency of collaboration. The same logic was used concerning the dependent variables, enabling us to examine whether co-authorship links, more precisely their existence and intensity, influence the references cited by researchers, in their existence and intensity. Thus, like the EI-Index analysis, different periods were considered for the regression models. In both cases, the data used were exclusively those that referred to the relationships mapped during each period under study, whether of co-authorship or intellectual similarity.

We used Ucinet 6 and Pajek 1.20 software to configure the co-authorship and intellectual similarity networks. The E-I Index algorithm and the MRQAP regression technique were also conducted using the Ucinet 6.

\section{RESULTS AND DISCUSSION}

\section{Social Dimension: Co-authorship Network}

The first step for answering our research question was the configuration of the co-authorship network for the period under study. Our aim was to characterize the social organization and to identify clusters based on collaboration patterns among researchers, since we believe that collaboration is a relevant indicator for reflecting on the social interaction involved in the construction of scientific knowledge. Collaboration relationships can reveal the sharing and diffusion of ideas, concepts and parameters for scientific practice - in this case, more specifically, those linked to the institutional analysis perspective. Figure 1 shows the collaboration structure among researchers based on coauthorship relationships.

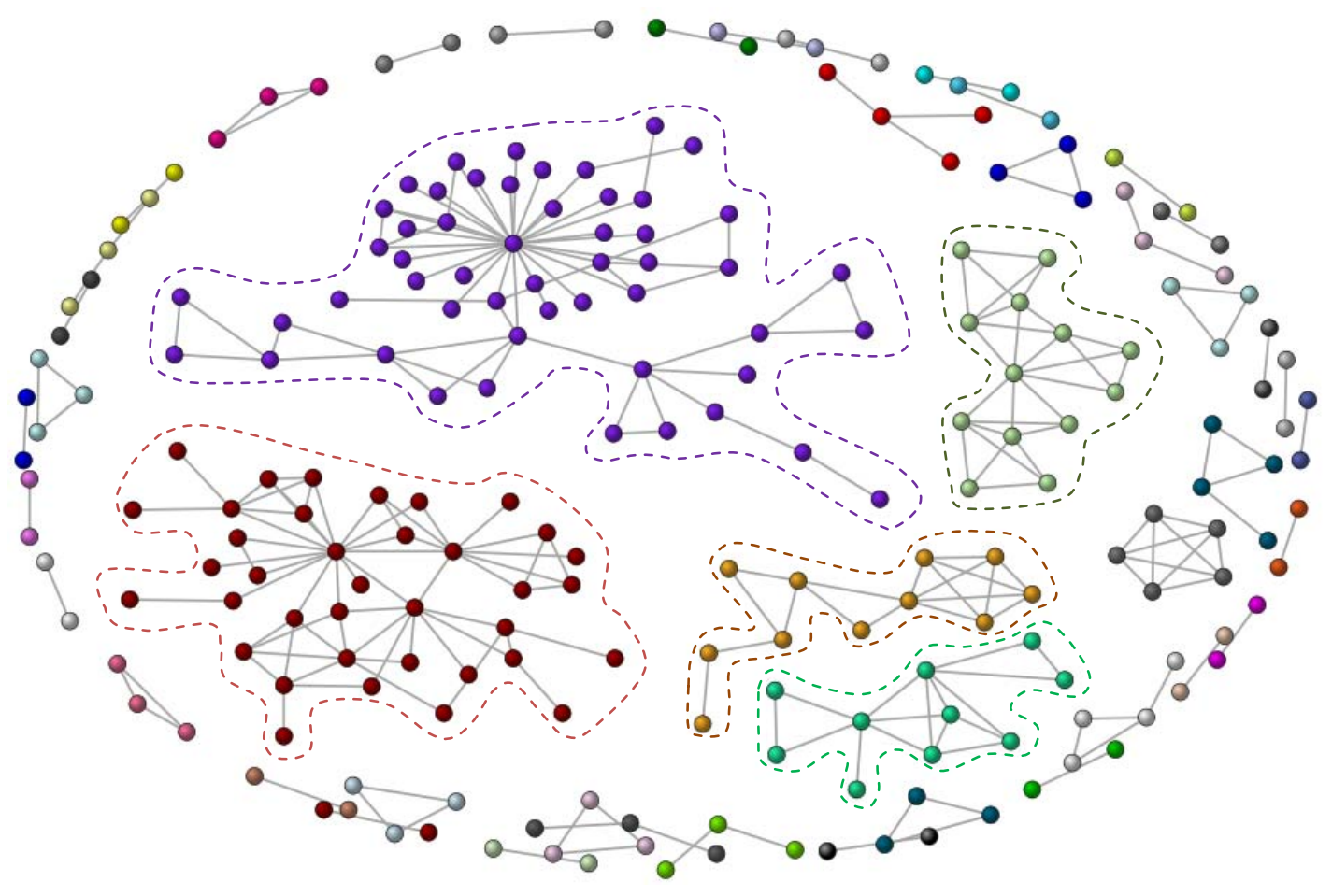

Figure 1 - Co-authorship relationship structure Source: research results. 
It is worth noting that this is a fragmented network, made up of several small components and isolated authors (whose are not represented in Figure 1). These surround five larger components that together account for $48.1 \%$ of the researchers. In contrast, as we pointed out in another study (see Guarido Filho, Machado-da-Silva, Gonçalves, 2009), the apparent disorganization of the network was accompanied by a greater local agglomeration of nodes, a sign that inequality in the formation of relationships could be a influence research practices and sharing of perspectives. At that time an organized growth of the network was observed, especially around continuant researchers who participate more frequently and regularly when it comes to scientific production ${ }^{6}$.

This situation, we speculated, would suggested "restricted communications between different parts of the network, which could be a tendency to form groups of researchers sharing different interests and preferences among themselves, whether epistemological, theoretical or thematic" (Guarido Filho, Machado-da-Silva, \& Gonçalves, 2009, p. 307). But, due to the scope of that work we did not discuss this point. However, from now on this will be the focus of the subsequent steps of research: to examine whether the social relationship pattern does indeed condition the cognitive structures of the groups of researchers, delimiting intellectual preferences.

\section{Shared Theoretical Framework}

With this purpose in mind, we began to research the intellectual structure that is subjacent to the analyzed texts. Our purpose was to evaluate whether there are indeed further signs that could lead us to believe that different clusters of researchers have different intellectual bases among themselves. Perhaps the simplest way for this would be to compare citation matrices, checking for differences between the references they used in their articles. That was what we did here, considering the five largest components of the social collaboration network. To facilitate visualization, the data were exposed in the form of a two-mode network, as shown in Figure 2, in which the color of the nodes indicates the degree of sharing of a cited author by the components (indegree centrality).

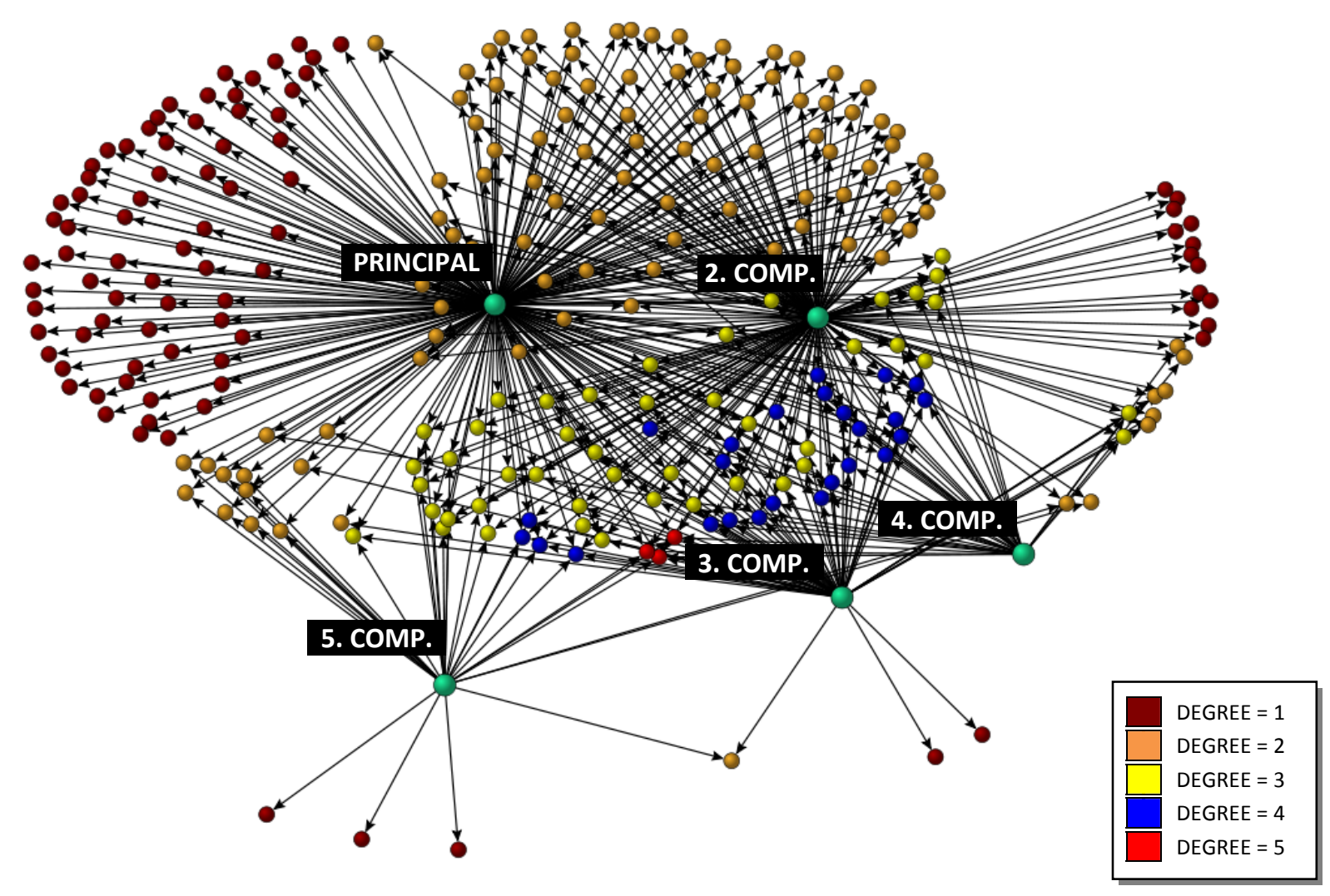

Figure 2 - Two-mode network for Larger Components and Cited Authors

Source: research results with authors cited eight or more times in the citing texts. 
The first point that deserves to be mentioned is the low number of authors that are cited by all or by at least four groups of researchers. This indicates that there is a set of cited authors that are found in the theoretical framework of practically all components. Indeed, they for the most part correspond to the foundational authors of the institutional analysis perspective in organizational studies and for this reason they are cited in the majority of articles published in the field. However, the important point is: if the contact points between components are rare, there seems to be space for disagreement among them, with several other authors being cited exclusively by one group or another.

By the observation of the two largest components (in the Figure 2: Principal and 2.Comp.), this is very clear. On the one hand, they have a significant volume of references in common, probably due to fact they concentrate the most part of researchers and a considerable part of the scientific production. Often, there are themes in common, such as organizational fields and institutionalization of organizational practices. On the other hand, we found a wide set of cited authors who are exclusively referenced by one of them, as shown in Figure 2 as being Degree 1 .

However, the information obtained here is exploratory and does not enable us to make completely definite statements about the social conditioning of the intellectual structure used by researchers from different groups. It does, however, emphasize evidence of specificity in the theoretical framework that is used by researchers according to the sets of co-authorships relations they have established. This, in a first glance, departs from a monolithic and universal character of scientific knowledge. Even though we are dealing with an analytical perspective with distinct and relatively identifiable nuclear properties, in accordance with the idea of institutional universals (Dacin, 1997, p. 823), the body of knowledge expressed in the institutional theory in organization studies is ongoing, in a permanent process of social construction. For the purpose of clarifying these aspects, different procedures were used.

\section{Intellectual Affinity}

First of all, as exposed in the methodological procedures section, once again we used the network analysis resource for this purpose, but in this case our aim was to evaluate the researchers according to the similarity of the references they used in their works. Note that this is not a co-authorship network, but a network in which the ties represent the similarity of the set of cited authors. The resulting network shows the intellectual affinity among researchers and can be seen in Figure 3.

In Figure 3, researchers with different citation profiles are represented by nodes that are distant from each other; the more distant, the more different the researchers are in terms of what they cite. Conversely, the closer the nodes are to each other, the more similar the researchers are in respect to the set of authors they usually cite. In this case, the proximity of researchers would reveal natural communities, i.e., sets of researchers who share the same intellectual base whether or not there are direct relationships for scientific production between them.

However, our fundamental research question has to do with the relationship between the social and intellectual dimension, interactively associated with the construction of scientific knowledge. Hence, for easier viewing, we applied different colors to the nodes depending on the component of the social network in which each researcher is included. This simple device enhances the analysis of the intellectual affinity by allowing us to discern properties that go beyond the individual researchers. 


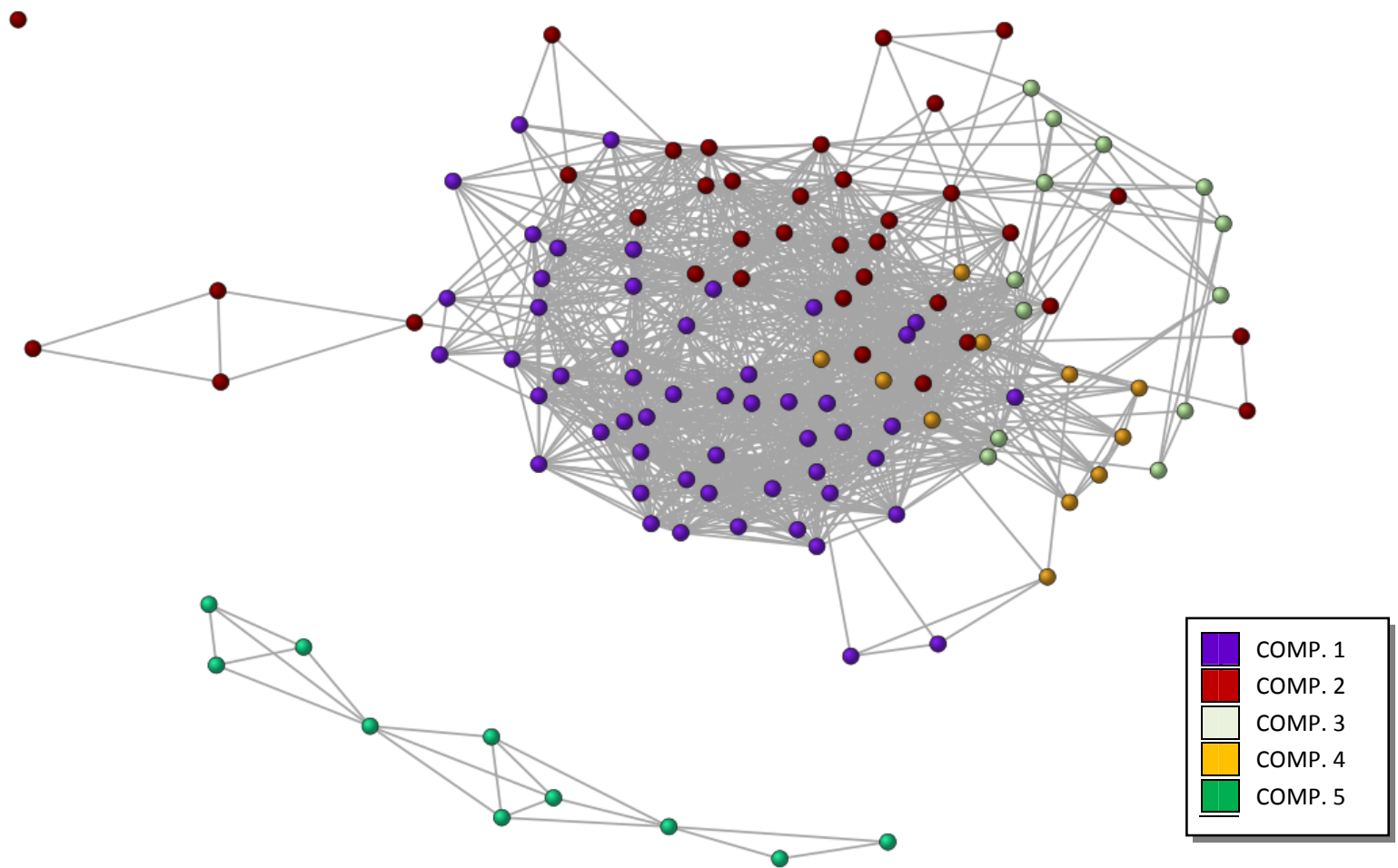

Figure 3 - Similarity of Researchers based on the Cited Authors

Note: To facilitate the visualization of the network, only ties with higher degrees of similarity are represented (greater than 0.3). For the same reason, researchers belonging to the peripheral components are also excluded, with only the members of the five largest remaining.

Source: research results.

The relevant point is the evidence of a strong correlation between these natural communities and coauthorship components, as was shown in the co-authorship network. It can be clearly seen that researchers from the same component tended to be closer to each other, reflecting their similarity in terms of the references they use. This means that the intellectual affinity of researchers, generated from the vectors of cited authors, converges for the social groups obtained from the co-authorship networks. Moreover, this result was not exclusively found in respect to the whole period under study (1993-2007), as depicted in Figure 3. Similar results come about when this procedure was replicated for shorter periods (1999-2001, 2002-2004, 2005-2007) and when the analysis considered a higher number of cited authors (516). In both situations the findings given here were reinforced: there is a strong relationship between the social and intellectual dimensions in the field under study. Statistical techniques back up these results as we can see in the next section.

\section{Strength of Embeddedness Through Ties}

The visual analysis of the intellectual affinity network has an important shortcoming, as it is not possible to understand the magnitude of the convergence between the dimensions. For this reason, we conducted the E-I Index test to jointly evaluate the rate to which connections between researchers in the intellectual affinity network occur with other members of the same component. As every connection in this network expresses a reference vector, i.e., a similar set of cited authors, the result of the E-I Index can be interpreted as a form of evaluating the conditioning of the intellectual structure through the social dimension. 
Table 1:

Degree of Externality of Relationships

\begin{tabular}{lccccc}
\hline & Period 1*) & Period 2 & Period 3 & Period 4 & Total \\
& $\mathbf{1 9 9 3 - 1 9 9 8}$ & $\mathbf{1 9 9 9 - 2 0 0 1}$ & $\mathbf{2 0 0 2 - 2 0 0 4}$ & $\mathbf{2 0 0 5 - 2 0 0 7}$ & $\mathbf{1 9 9 3 - 2 0 0 7}$ \\
\hline E-I Index & --- & -0.892 & -0.411 & -0.032 & -0.214 \\
Sig. & --- & --- & --- & $\mathrm{p}<0.05$ & $\mathrm{p}<0.05$ \\
\hline
\end{tabular}

Note. $(*)$ The data are insufficient to calculate the E-I Index.

Source: research results.

As shown in Table 1, in the different periods under study, the indicators were negative, which indicates a propensity of the ties to concentrate internally within components. This result, besides emphasizing the idea that the relationships within a given component tend to influence the knowledge framework used as a basis in studies, it also implies that the cognitive structure of a component is more likely to serve as a theoretical foundation than those that are predominant in other parts of the field.

Strength of direct ties. The E-I Index test enabled us to ascertain the aggregate effect, for each component, of the social collaboration network on its respective intellectual structures. To complement this, it is possible to consider the influence of direct collaboration relationships on the researchers' citation profiles. Thus, we used the MRQAP multiple regression technique to evaluate whether dyadic co-authorships ties influence intellectual affinity considering the existence and intensity of relationships among researchers.

The regression models were generated for the whole period under analysis and also for shorter periods, as specified in the methodological procedures section. The results concerning influence on the intensity of intellectual affinity are shown in Table 2. Meanwhile, Table 3 shows the influence of coauthorships relations on the existence of intellectual affinity among researchers. The former analysis use valued data while the later is restricted to binary/dichotomous data.

Table 2:

MRQAP for the Relationship between Intensity of Intellectual Affinity (valued) and Collaboration between Researchers

\begin{tabular}{lccccc}
\cline { 2 - 5 } Variables & Model 1 & Model 2 & Model 3 & Model 4 & Model 5 \\
\cline { 2 - 5 } Co-Authorship & $1993-2007$ & $2005-2007$ & $2002-2004$ & $1999-2001$ & $1993-1998$ \\
(frequency) & 53.641 & 53.164 & 41.469 & 36.727 & 28.711 \\
\hline Co-Authership & $(-0.553)^{* * *}$ & $(-0.662)^{* * *}$ & $(-0.668)^{* * *}$ & $(-0.774)^{* * *}$ & $(-0.867)^{* *}$ \\
(ties) & -31.589 & -27.785 & -22.896 & -15.756 & 17.252 \\
Intercept & $(-0.178)^{* * *}$ & $(-0.224)^{* * *}$ & $(-0.290)^{* * *}$ & $(-0.254)^{* *}$ & $(-0.118)$ \\
\hline $\mathrm{R}^{2}$ & 7.436 & 6.49 & 6.623 & 8.029 & 12.143 \\
Sig & 0.176 & 0.229 & 0.167 & 0.293 & 0.931 \\
$\mathrm{~N}$ & $\mathrm{p}<0.001$ & $\mathrm{p}<0.001$ & $\mathrm{p}<0.001$ & $\mathrm{p}<0.001$ & $\mathrm{p}<0.05$ \\
\hline
\end{tabular}

Note. ${ }^{*} \mathrm{p}<0.1 ;{ }^{* *} \mathrm{p}<0.05 ;{ }^{* * *} \mathrm{p}<0.001$

Standard Error in brackets 
Table 3:

\section{MRQAP for the Relationship between the existence of Intellectual Affinity (dichotomous) and Collaboration between Researchers}

\begin{tabular}{lcccc}
\cline { 2 - 5 } Variables & Model 1 & Model 2 & Model 3 & Model 4 \\
\cline { 2 - 5 } Co-Authorship & $1993-2007$ & $2005-2007$ & $2002-2004$ & $1999-2001$ \\
(frequency) & 0.000 & 0.000 & 0.00001 & -0.000007 \\
\hline Co-Authorship & $(0.000)$ & $(0.000)$ & $(0.000)$ & $(0.000)$ \\
(ties) & 0.229 & 0.223 & 0.251 & -0.105 \\
\hline Intercept & $(-0.488)^{* * *}$ & $(-0.056)^{* *}$ & $(-0.073)^{* *}$ & $(-0.105)$ \\
\hline $\mathrm{R}^{2}$ & 0.771 & 0.772 & 0.815 & 0.815 \\
Sig & 0.002 & 0.003 & 0.011 & 0.011 \\
\hline
\end{tabular}

Note. ${ }^{*} \mathrm{p}<0.1 ; * * \mathrm{p}<0.05 ; * * * \mathrm{p}<0.001$

Model 5, for period 1 (1993-1998), could not be calculated.

Standard Error in brackets

Considering the intensity of intellectual affinity as a dependent variable (the valued data), it could be seen in Table 2 that the explanatory power of the different models varied between $16.7 \%$ and $93.1 \%$, with evidence of a strong association both in terms of the existence and intensity of co-authorship ties. These findings show that the strength of intellectual affinity tends to be greater the more frequently the researchers relate to one another.

However, when the dependent variable became the existence of intellectual affinity (treating the relations dichotomously), all the models showed very low explanatory power, despite being significant. At first sight, this result appears contradictory to the previous findings, but in fact it strengthens them. This is because there are authors who are cited by a wide range of researchers, especially those who are considered as foundational in the institutional perspective. Because they are widely known authors, significant differences concerning intellectual affinity will only appear when it is taking into consideration the intensity with which they are cited. This is in accordance with the previous analysis, revealing considerable influence of dyadic cooperation relationships in the approach adopted by the researchers.

All these findings from the intellectual affinity network, the E-I Index and the MRQAP regression analyses are complementary in that they show the existence of mechanisms that act in the construction of scientific knowledge through the interaction of the social and intellectual dimensions. The effect of the groups and local relationships has proved to be relevant, showing that the construction of scientific knowledge does not happen at random, although this does not mean that it is planned or predictable.

Focusing on the largest components, there appears to be an embeddedness mechanism by which researchers tend to share a common nucleus of references, irrespective of maintaining co-authorship ties among themselves and which differentiate them from other components. Thus, we can speculate that they reflect socialization processes through which new researchers, for instance, tend to follow ideas and perspectives, at least at the fundamental level, that have already been constructed and shared at the local level by older researchers. Therefore, a new relationship in the component seems to suffer with the existing relationships, which have a certain power to promote intellectual alignment.

Therefore, it makes sense to admit that the social connections among researchers facilitate the spreading of ideas generated in the context of scientific production. Nevertheless, our findings are related to the degree to which shared understandings are perceived by researchers in relation to what is 
practiced in a certain field, thus serving as a guide for the diffusion of ideas, either by giving continuity to that which is perceived as a suitable model or by social embeddedness.

To better understand the results shown so far, it is worth interpreting them in the context of the findings of Guarido Filho, Machado-da-Silva and Gonçalves (2009), whose research longitudinally mapped the field of the institutional perspective in organizational studies through social networks and the categorization of researchers in terms of their regularity and productivity from 1993 to 2007. Among other aspects, their findings show that the quantitative expansion in terms of researchers and articles in the field took place in an organized way in the form of social co-authorship groups around researchers classified as continuants and transients, who exerted a relevant role of intermediating relationships and consolidating production.

Guarido Filho, Machado-da-Silva and Gonçalves (2009) admitted in their study the possibility that relational mechanisms, especially concerning the intermediation and stratification of relationships among researchers might influence the consumption and acceptance of certain ideas, the way new research is conducted, and the shared understandings among the members of each social cluster. However, the data did not enable them to relate their findings with the influence of social organization of the components on the provision of methods, approaches and theoretical frameworks. This has only been made possible through the results of the present study, confirmed by the E-I Index and the MRQAP technique.

Interpreting the two studies together, we can conclude that, besides showing evident linkages of collaboration among researchers, co-authorships relationships reflect social processes that extrapolate the dyadic relation among researchers. In other words, although it is clear that in collaboration relationships researchers share common theoretical frameworks, the results of this investigation show a structural dimension at the level of shared understandings that overlaps the direct ties between them and that do not depend on them. On the one hand, this refers to socialization processes connected to intellectual qualification, which are active in this sense; on the other hand, it is concerned with the intellectual contours themselves that favor a certain perspective, homogenizing the intellectual structure and shaping social and symbolic boundaries.

\section{CONCLUSIONS}

In this study we investigated the process of constructing scientific knowledge from the analysis of social conditioning on the intellectual structure. In this sense, we used different analytical resources in order to examine the influence of the characteristics of the collaboration structure among researchers on the prevailing substantive content of their work. Our focus was restricted to the works based on the institutional perspective in organizational studies published in academic outlets in Brazil.

We opted to consider scientific production in the form of articles as a source of data for this analysis because we recognize that articles are also symbolic elements in that they condense the language in the agents' contexts of meaning (Guarido Filho, 2008). As such, they are consumed and, therefore, continually interpreted and modified throughout the process of transmission of ideas. Moreover, they express social practices, bearing not only widely shared knowledge but also values and ideas in how they are organized and communicated (Giddens, 1987; Scott, 2003).

The results, jointly interpreted with those already published by Guarido Filho, Machado-da-Silva and Gonçalves (2009), point in this direction. Thus, while certain research sources, authors and texts have become widespread, others have remained restricted to relatively well defined social contours, flourishing among some groups of researchers but largely ignored by others. Differences in intellectual structure associated to different collaborative groups were identified. Evidence was found of the influence of the social dimension on the intellectual affinity that exists among researchers, revealing that in addition to the aspects concerned to the stratification and central role played especially by 
continuant and transient authors, the social organization of components has a specific substantive grounding in terms of shared theoretical frameworks and, in their turn, guidance for scientific production.

Such results, in principle, are related to the choices made by researchers throughout their scientific production activity, be it in how they establish collaboration relationships with their peers, be it in the basis of references used to further develop their works. However, the construction of scientific knowledge, as is the case of the institutional perspective studied herein, is not limited to intentional actions of certain researchers or groups of researchers, although it is also dependent on them. Therefore, although scientific knowledge might be defined paradigmatically, regarding its intellectual program as defended by the agents when they carry out scientific activities, the implications discussed so far favor it being understood as an ongoing social process, related to broader social and cognitive structures.

Consequently, we defend the idea that the articulation between the social and intellectual dimensions in this process cannot be understood in a linear fashion, from one dimension to the other, but rather recursively, considering their mutual influence. In this sense, the practice of scientific production is understood as guided by cognitive resources (disposed as intellectual structure) and relational resources, in addition to directives for the legitimacy and promotion of the knowledge claims; even so, at the same time, it created conditions for new actions, in a recurrent process of knowledge construction.

It remains to be said that the relationships are not isolated from the intellectual structure; on the contrary, they make sense and ensure legitimacy of a given theoretical perspective. Thus, if the construction of the institutional perspective involves the diffusion of new ideas, this implies that they have been consumed and articulated with the knowledge in the field. As they are incorporated into new works, they also undergo a social evaluation, so that, if they are accepted, they can enjoy existing cooperation channels to be further diffused.

In this way, the interaction between the social and intellectual dimensions extrapolates not only the most immediate relationships but also social groups and thus there can be more widespread sharing in the intellectual dimension between different groups of researchers irrespective of the collaboration ties that exists among them. In other words, natural communities can be extended beyond the groups, reproducing shared cognitive frameworks and orienting new practices since scientific knowledge, as a social product in the form of a text, crosses temporal and spatial frontiers.

To conclude, we should highlight interesting implications: on the one hand, we found a certain degree of specificity of intellectual structures in the different groups of researchers, showing idiosyncratic ways of conceive and producing scientific knowledge; on the other hand, the conditions for reproducing scientific knowledge also involves wider frameworks connected to cognitive structures that are more far reaching than that of the network. The conditioning of the social dimension on the intellectual, repositioned in the form of recursive articulation, therefore, is multileveled with mechanisms and effects occurring at different levels of aggregation.

\section{NOTES}

\footnotetext{
${ }^{1}$ Relational techniques are also common in scientometrics such as co-authorship, co-citation or co-occurrence of words.

${ }^{2}$ Cited by Cronin (1995, p. 10).

3 Organizational institutionalism, as an analytical perspective, was effectively launched in Brazil in a study conducted by Machado-da-Silva in 1991, in accordance with Caldas, M. P., \& Fachin, R. (2007). Paradigma funcionalista: desenvolvimento de teorias e institucionalismo nos anos 1980 e 1990. In M. P. Caldas \& C. O. Bertero (Eds.), Teoria das organizações (pp. 69-79). São Paulo: Atlas. However, this work is not part of the body of work analyzed in this article since it had not been published among the selected sources for data collection.
} 


\footnotetext{
${ }^{4}$ The following publications were research sources: Revista de Administração de Empresas [ERA], Revista de Administração de Empresas Eletrônica [RAE-E], Revista de Administração da Universidade de São Paulo [RAUSP], Revista de Administração Contemporânea [RAC], Revista de Administração Contemporânea Eletrônica [RAC-E], Revista de Administração Pública [RAP], Organizações \& Sociedade [O\&S], Revista Eletrônica de Administração [REAd], Revista BASE, Cadernos EBAPE.br, Revista de Administração Mackenzie [RAM], Brazilian Administration Review [BAR], proceedings of the annual congresses of the Brazilian Academy of Management: overall meetings [EnANPAD], organizational studies meetings [Ếneo], and strategic studies meetings [3Es]. The journals evaluated for the year of 2007 were limited to those that had been made available up to the final date of data collection, with the last editions consulted being: RAE-E, 6(2); RAE, 47(4); RAP, 41(5); Cadernos EBAPE, 5(4); RAC, 11(4); RAC-E, 1(3); BAR, 4(3); RAUSP, 42(4); READ, 13(3); RAM, 8(4); BASE, 4(3); O\&S, 14(2).

${ }^{5}$ The correlation measurement for citations was the cosine, in accordance with Chen. C. (2006). Information visualization: beyond the horizon (2nd ed). London: Springer, who highlights its suitability for this type of study.

${ }^{6}$ For a more detailed discussion on the results concerning the social dimension analysis, see Guarido Filho, Machado-daSilva and Gonçalves (2009) and Guarido Filho (2008).
}

\section{REFERENCES}

Acedo, F., Barroso, C., Casanueva, C., \& Galán, J. (2006). Co-authorship in management and organizational studies: an empirical and network analysis. Journal of Management Studies, 43(5), 957-983.

Alexander, J. C., \& Smith, P. (2002). The strong program in cultural theory: elements of a structural hermeneutics. In J. Turner (Ed.), Handbook of sociological theory (pp. 135-150). New York: Kluwer Academic/Plenum Publishers.

Astley, W. G. (1985). Administrative science as socially constructed truth. Administrative Science Quarterly, 30(4), 497-513.

Barabasi, A., Jeong, H., Néda, Z., Ravasz, E., Schubert, A., \& Vicsek, T. (2002). Evolution of The Social Network of Scientific Collaborations. Physica A, 311(3), 590-614.

Bowring, M. A. (2000). De/constructing theory: a look at the institutional theory that positivism built. Journal of Management inquiry, 9(3), 258-270.

Braga, M. J. C., Gomes, L. F. A. M., \& Ruediger, M. A. (2008). Mundos pequenos, produção acadêmica e grafos de colaboração: um estudo de caso dos Enanpads. Revista de Administração Pública, 42(1), 133-154.

Cronin, B. (1984). The citation process: the role and significance of citations in scientific communication. London: Taylor Graham.

Cronin, B. (1995). The scholar's courtesy: the role of acknowledgement in the primary communication process. London: Taylor Graham.

Cronin, B. (2004). Normative shaping of scientific practice: the magic of Merton. Scientometrics, 60(1), 41-46.

Cronin, B. (2008). The sociological turn in information science. Journal of Information Science, 34(4), 465-475.

Dacin, M. T. (1997). Institutions and organizations. Administrative Science Quarterly, 42(4), 821-824.

Davis, G. F. (2006). Mechanisms and the theory of organizations. Journal of Management Inquiry, 15(2), 114-118. 
Dekker, D., Krackhardt, D., \& Snijders, T. A. B. (2007). Sensitivity of MRQAP tests to collinearity and autocorrelation conditions. Psychometrika, 72(4), 563-581.

DiMaggio, P. (1995). Comments on "What theory is not". Administrative Science Quarterly, 40(3), 391-397.

DiMaggio, P., \& Powell, W. W. (1991). Introduction. In W. W. Powell \& P. DiMaggio (Eds.), The new institutionalism in organizational analysis (pp. 1-38). Chicago: University of Chicago Press.

Fuller, S. (2002). Social epistemology (2nd ed.). Bloomington: Indiana University Press.

Giddens (1984). The constitution of society. Cambridge: Polity Press.

Giddens, A. (1987). Structuralism, post-structuralism and the production of culture. In A. Giddens \& J. Turner (Eds.), Social theory today (pp. 195-223). Stanford: Stanford University Press.

Glanzel, W., \& Schubert, A. (2008). Analysing Scientific Networks through Co-Authorship. In H. F. Moed, W. Glänzel, \& U. Schmoch (Eds.), Handbook of quantitative science and technology research (pp. 257-276). New York: Kluwer Academic Publishers.

Guarido Filho, E. R. (2008). A construção da teoria institucional nos estudos organizacionais no Brasil: o período 1993-2007. Tese de doutorado, Universidade Federal do Paraná, Curitiba, PR, Brazil.

Guarido Filho, E. R., Machado-da-Silva, C. L., \& Gonçalves, S. A. (2009). Organizational Institutionalism in the Academic Field in Brazil: social dynamics and networks. Brazilian Administration Review, 6(4), 299-315.

Hanneman, R. A., \& Riddle, M. (2005). Introduction to social network methods. Riverside: University of Califórnia.

Hasselbladh, H., \& Kallinikos, J. (2000). The project of rationalization: a critique and reappraisal of neo-institutionalism in organization studies. Organization Studies, 21(4), 697-720.

Hirsch, P. (1997). Sociology without social structure: neoinstitutional theory meets brave new world. American Journal of Sociology, 102(6), 1702-1723.

Hoffman, A. J. (1999). Institutional evolution and change: environmentalism and the U.S. chemical industry. Academy of Management Review, 42(4), 351-371.

Krackhardt, D., \& Stern, R. (1988). Informal networks and organizational crises: an experimental simulation. Social Psychology Quarterly, 51(2), 123-140.

Kropf, S. M., \& Lima, N. T. (1999). Os valores e a prática institucional da ciência: as concepções de Robert Merton e Thomas Kuhn. História, Ciências, Saúde-Manguinhos, 5(3), 1-17.

Kuhn, T. S. (1970). The structure of scientific revolutions (2nd ed.). Chicago: University of Chicago Press.

Kuhn, T. S. (1977). The essential tension. Chicago: University of Chicago Press.

Kuhn, T. S. (1990). The road since structure. Proceedings of the Biennial Meeting of the Philosophy of Science Association, Volume Two: Symposia and Invited Papers, Chicago, Il, USA.

Leydesdorff, L. (1998). Theories of citation? Scientometrics, 43(1), 5-25.

Leydesdorff, L. (2001). The challenge of scientometrics: the development, and self-organization of scientific communications (2nd ed). USA: Universal Publishers. 
Leydesdorff, L., \& Amsterdamska, O. (1990). Dimensions of citation analysis. Science, Technology and Human Values, 15(3), 305-335.

Li-Chun, Y., Kretschmer, H., Hanneman, R. A., \& Ze-Yuan, L. (2006). Connection and stratification in research collaboration: an analysis of the COLLNET network. Information Processing \& Management, 42(6), 1599-1613.

Liu, X., Bollen, J., Nelson, M. L., \& Van de Sompel, H. (2005). Co-authorship networks in the digital library research community. Information Processing \& Management, 41(6), 1462-1480.

Machado-da-Silva, C. L., \& Gonçalves, S. (1997). Nota técnica: a teoria institucional. In S. R Clegg, C. R. Hardy, \& W. R. Nord (Eds.), Handbook de estudos organizacionais (pp. 220-226). São Paulo: Atlas.

Machado-da-Silva, C. L., \& Rossoni, L. (2007). Persistência e mudança de temas na estruturação do campo científico da estratégia em organizações no Brasil. Revista de Administração Contemporânea, 11(4), 33-58.

Machado-da-Silva, C. L., Fonseca, V. S., \& Crubellate, J. M. (2005). Estrutura, agência e interpretação: elementos para uma abordagem recursiva do processo de institucionalização. Revista de Administração Contemporânea, 9(Ed. Especial, 1), 9-39.

Machado-da-Silva, C. L., Guarido Filho, E. R., \& Rossoni, L. (2006). Organizational fields and the structuration perspective: analytical possibilities. Brazilian Administration Review, 3(2), 159196.

Machado-da-Silva, C. L., Guarido Filho, E. R., Nascimento, M. R., \& Oliveira, P. T. (2003). Institucionalização da mudança na sociedade brasileira: o papel do formalismo. In. M. M. F. Vieira \& C. A. Carvalho (Eds.), Organizações, instituições e poder no Brasil (pp. 179-202). Rio de Janeiro: Editora FGV.

Merton, R. K. (1957). Priorities in scientific discovery: a chapter in the sociology of science. American Sociological Review, 22(6), 635-659.

Merton, R. K. (1968). The Matthew effect in science. Science, 159(3810), 56-63.

Merton, R. K. (1988). The Matthew effect in science, II: cumulative advantage and the symbolism of intellectual property. Isis, 79(4), 606-623.

Merton, R. K. (1996). On social structure and science. Chicago: Chicago Univ. Press.

Misoczky, M. C. (2003). Poder e institucionalismo: uma reflexão crítica sobre as possibilidades de interação paradigmática. In M. M. F. Vieira, \& C. A. Carvalho (Eds.), Organizações, instituições e poder no Brasil (pp. 141-176). Rio de Janeiro: Editora FGV.

Moody, J. (2004). The structure of a social science collaboration network: disciplinary cohesion from 1963 to 1999. American Sociological Review, 69(2), 213-238.

Mullins, N. C. (1973). Theories and theory groups in contemporary American sociology. London: Harper \& Row.

Newman, M. E. J. (2001b). Scientific collaboration networks I: network construction and fundamental results. Physical Review E, 64(1), 1-8.

Newman, M. E. J. (2001a). The structure of scientific collaboration networks. Proceedings of National Academic Sciences, 98(2), 404-409. 
Otte, E., \& Rousseau, R. (2002). Social network analysis: a powerful strategy, also for the information sciences. Journal of Information Science, 28(6), 441-453.

Rossoni, L., \& Guarido Filho, E. R. (2007). Cooperação interinstitucional no campo da pesquisa em estratégia. Revista de Administração de Empresas, 47(4), 74-87.

Rossoni, L., \& Guarido Filho, E. R. (2009). Cooperação entre programas de pós-graduação em administração no Brasil: evidências estruturais em quatro áreas temáticas. Revista de Administração Contemporânea, 13(3), 366-390.

Rossoni, L., Guarido Filho, E. R., \& Machado-da-Silva, C. L. (2008, junho). Centralidade, Produtividade e escolha preferencial: o papel da agência na construção do conhecimento científico em organizações e estratégia no Brasil. Anais do Encontro de Estudos Organizacionais, Belo Horizonte, MG, Brasil, 5.

Rossoni, L., Hocayen-da-Silva, A. J., \& Ferreira, I., Jr. (2008). Aspectos estruturais da cooperação entre pesquisadores no campo da administração pública e gestão social: análise das redes entre instituições no Brasil. Revista de Administração Pública, 47(6), 1041-1067.

Scott, W. R. (2001). Institutions and organizations (2nd ed.). Thousand Oaks: Sage.

Scott, W. R. (2003). Institutional carriers: reviewing modes of transporting ideas over time and space and considering their consequences. Industrial and Corporate Change, 12(4), 879-894.

Selznick, P. (1996). Institutionalism "old" and "new". Administrative Science Quarterly, 41(2), 270277.

Small, H. (2004). On the shoulders of Robert Merton: towards a normative theory of citation. Scientometrics, 60(1), 71-79.

Van Raan, A. F. J. (1997). Scientometrics: state-of-the-art. Scientometrics, 38(1), 205-218.

Wagner, C. S., \& Leydesdorff, L. (2005). Network structure, self-organization, and the growth of international collaboration in science. Research Policy, 34(10), 1608-1618.

Wasserman, S., \& Faust, K. (1994). Social network analysis: methods and applications. Cambridge: Cambridge University Press.

Weick, K. E. (1995). What theory is not, theorizing is. Administrative Science Quarterly, 40(3), 385397.

Wouters, P. (1999). The citation culture. Doctoral thesis, Faculteit der Scheikunde, University of Amsterdam, Amsterdam, Netherlands. 